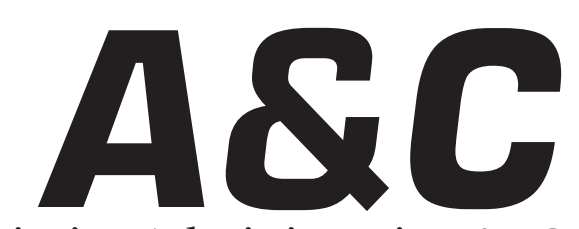

Revista de Direito Administrativo \& Constitucional

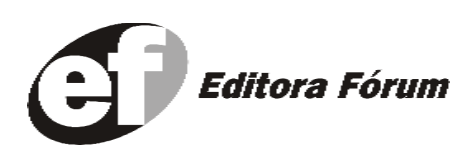

A\&C R. de Dir. Administrativo e Constitucional, Belo Horizonte, ano 4, n.16, p. 1-255, abr.jun. 2004 


\section{A\&C REVISTA DE DIREITO ADMINISTRATIVO E CONSTITUCIONAL}

\section{IPDA}

Instituto Paranaense

de Direito Administrativo

Direção Geral

Romeu Felipe Bacellar Filho

Direção Editorial

Paulo Roberto Ferreira Motta

Direção Executiva

Emerson Gabardo

Conselho de Redação

Edgar Chiuratto Guimarães

Adriana da Costa Ricardo Schier

Célio Heitor Guimarães

Conselho Editorial

\section{Adilson Abreu Dallari Lúcia Valle Figueiredo}

Alice Gonzáles Borges Manoel de Oliveira Franco Sobrinho

Carlos Ari Sundfeld (in memoriam)

Carlos Ayres Britto Marçal Justen Filho

Carlos Delpiazzo Marcelo Figueiredo

Cármen Lúcia Antunes Rocha Márcio Cammarosano

Celso Antônio Bandeira de Mello Maria Cristina Cesar de Oliveira

Clèmerson Merlin Clève Nelson Figueiredo

Clóvis Beznos Odilon Borges Junior

Enrique Silva Cimma Pascual Caiella

Eros Roberto Grau Paulo Eduardo Garrido Modesto

Fabrício Motta Paulo Henrique Blasi

Guilhermo Andrés Muñoz Paulo Neves de Carvalho

Jorge Luís Salomoni Paulo Ricardo Schier

José Carlos Abraão Pedro Paulo de Almeida Dutra

José Eduardo Martins Cardoso Regina Maria Macedo Nery Ferrari

José Luís Said Rogério Gesta Leal

José Mario Serrate Paz Rolando Pantoja Bauzá

Juan Pablo Cajarville Peruffo Sérgio Ferraz

Juarez Freitas Valmir Pontes Filho

Julio Rodolfo Comadira Yara Stropa

Luís Enrique Chase Plate Weida Zancaner

Os conceitos emitidos em trabalhos assinados são de responsabilidade de seus autores, que gozam de inteira liberdade de opinião. e-mail para remessa de artigos, pareceres e contribuições: e.gab.@uol.com.br

ou conselho@editoraforum.com.br Endereço para envio de contribuições: Editora Fórum

Revista A\&C, Av. Afonso Pena, 2770, 15\%16ª andar, Funcionários, CEP 30130-007 - Belo Horizonte - MG

A\&C Revista de Direito Administrativo e Constitucional. Ano 3, n. 11, jan./mar. 2003. Belo Horizonte: Fórum, 2003.

Trimestral

ano 1, n.1, 1999 até ano 2, n.10, 2002 publicada pela Editora Juruá em Curitiba

ISSN: $1516-3210$

1. Direito Administrativo. 2. Direito Constitucional. I. Fórum.

CDD: 342 CDU: 33.342
Editor responsável: Luis Cláudio Rodrigues Ferreira Projeto gráfico: Luis Alberto Pimenta

Diagramação: Anderson Pimenta

Revisora: Olga M. A. Sousa

Pesquisa jurídica: Fátima Ribeiro - OAB/MG 74868 Bibliotecária: Nilcéia Lage de Medeiros -

CRB 1545/MG - 6 a região

(C) Editora Fórum Ltda 2004.

Proibida a reprodução total ou parcial desta obra, por qualquer meio eletrônico, inclusive por processos xerográficos, sem autorização expressa do editor.

Distribuída em todo o território nacional

Assinaturas e comercialização:

Editora Fórum, Av. Afonso Pena, 2770, 15-16 andar, Funcionários, CEP 30130-007 - Belo Horizonte - MG Tel.: (31) 2121-4900 - 0800 704-3737

e-mail: editoraforum@editoraforum.com.br site: www.editoraforum.com.br 


\title{
La Participación en la Nueva Ley de Medidas para la Modernización del Gobierno Local
}

\author{
Jaime Rodríguez-Arana Muñoz \\ Profesor Catedrático de Derecho Administrativo de la Universidad de La Coruña - Espanha. Pre- \\ sidente de la Asociación Española de Ciencias Administrativas
}

\begin{abstract}
Sumário: I Introducción - II La ley de medidas para la modernización del gobierno local en el marco de la reforma administrativa - III Reformismo y apertura a la realidad - IV Sobre la participación - V La OCDE y la participación - VI El espacio local: el espacio de la participación - VII La participación en la ley de medidas para la modernización local
\end{abstract}

\section{Introducción}

La reforma del régimen local que estamos comentando constituye, estoy seguro, un paso adelante muy relevante en orden a dotar a la realidad local española del traje jurídico necesario que haga posible que, en efecto, el espacio local sea el espacio territorial llamado, de forma especial, a la mejora real de las condiciones de vida de los ciudadanos.

Es sabido que entre los objetivos de la ley se encuentra, junto a la necesidad de superar el rígido y uniforme modelo organizativo, racionalizando y modernizando los gobiernos y administraciones locales, la aspiración a mejorar e impulsar la participación vecinal. En este punto, objeto de nuestro estudio, es muy importante llamar la atención sobre la importancia de la participación real de los ciudadanos puesto que hoy por hoy, es el centro de todos los procesos y proyectos de reforma administrativa en curso en tantos y tantos países del mundo, y en tantas y tantas Administraciones para, efectivamente, abrir espacios y cauces anchos y andaderos por las que discurra la participación libre de los vecinos.

En todos los intentos por propiciar la participación, nos encontraremos con la necesidad de subrayar que el ciudadano ha superado ya, o debe superar, esa perspectiva pasiva desde la cual únicamente era receptor de bienes y servicios que el todopoderoso Estado de Bienestar le suministraba desde la cuna hasta la tumba. Hoy, a lo que se aspira en los modernos programas de reforma administrativa, es a que los vecinos, auténticos propietarios de las instituciones públicas locales, asuman su papel y se dedican a protagonizar, desde la posición que les es propia, la configuración, A \& C R. de Dir. Administrativo e Constitucional, Belo Horizonte, ano 4, n. 16, p. 29-64, abr./jun. 2004 
definición y ejecución de las más importantes políticas públicas locales. Para ello, claro está, el legislador debe facilitar el camino y abrir los cauces para que el interés general, también en el plano local, se abra a una nueva dimensión en la que los postulados del pensamiento abierto, plural, dinámico y complementario brillen con luz propia. Quiere esto decir, entre otras cosas, que siendo el espacio local es el espacio de la gestión por antonomasia es, en su seno, donde la participación libre o la libre participación puede producir los frutos deseados de luz y color en el conjunto de las políticas locales.

En esta tarea, la concreta regulación de la participación en la Ley de medidas para la modernización local, debe ir precedida del estudio de las nuevas políticas públicas y la participación; en concreto, del protagonismo que ocupa, por derecho propio, la participación en la reforma administrativa del tiempo presente.

\section{La ley de medidas para la modernización del gobierno local en el marco de la reforma administrativa}

La ley que ahora analizamos se enmarca en las modernas tendencias de la reforma administrativa en lo que son los aspectos que vamos a estudiar a continuación. Hoy, no lo olvidemos, la posición del ciudadano, del vecino en los espacios locales, ha cambiado sustancialmente en la medida en que es el destinatario real de los servicios municipales y, sobre todo, porque en un entorno democrático como el que todos disfrutamos las instituciones públicas - Gobiernos y Administraciones —, son de la gente. Las estructuras y los empleados públicos que en ellas trabajan cobran sentido en la medida en que su actividad es presidida por la consideración de que el interés general está vinculado a la mejora de las condiciones de vida de la gente y a la promoción de todos y cada uno de sus derechos fundamentales.

Para ello, junto a la especial sensibilidad del legislador, que le ha llevado a ampliar el elemento de los derechos de los vecinos (artículo 18) y a facilitar la participación a través de los Distritos (artículo 128), del Consejo Social (artículo 131) o de la Comisión de sugerencias y Reclamaciones (artículo 132), debe subrayarse el acierto de articular un tratamiento jurídico - organizativo especial para el fenómeno urbano, la solución a la ausencia de cobertura legal para la potestad sancionadora, la nueva regulación de las formas de gestión de los servicios públicos locales... Aspectos, todos ellos, propios de la agenda de la reforma administrativa.

La preocupación por los distintos procesos de lo que ha venido a

A \& C R. de Dir. Administrativo e Constitucional, Belo Horizonte, ano 4, n. 16, p. 29-64, abr.jun. 2004 
denominarse reforma o modernización administrativa es constante a lo largo de los últimos tiempos, en los que se han sucedido intentos y propuestas para buscar la adecuación estructural y funcional de Administraciones locales orientadas a la prestación de nuevos servicios públicos y a la realización de actividades públicas en consonancia con el dinamismo social.

En términos generales, las transformaciones observadas en los países desarrollados desde una perspectiva de la gestión pública son bastante similares. Todo un conjunto de fenómenos como la preocupación por la eficacia pública, la búsqueda de la calidad en la prestación de los servicios públicos con la consiguiente orientación al ciudadano, supuestos de descentralización territorial y funcional, mayor participación de los ciudadanos así como de las organizaciones no gubernamentales en la gestión de servicios, etc., son intentos de reducir el exceso de leyes y reglamentos y, al tiempo, fórmulas para generar instrumentos que fortalezcan la idea de servicio público, tan necesaria hoy en día.

La práctica totalidad de los procesos de reforma y modernización administrativa se declaran dirigidos a conseguir una Administración pública más eficaz, que cueste menos y que piense más en el ciudadano. De esta manera, se pone de manifiesto un dato de importancia capital: los modelos políticos y administrativos han de construirse a partir del ciudadano y en función de sus necesidades colectivas. Esto es, en mi opinión, el "punctum dolems" de cualquier proceso de reforma o modernización administrativa: que se tenga bien claro que el dueño, que el propietario de la Administración pública es el ciudadano, en el caso presente, el vecino. De ahí, pues, el empeño del legislador en potenciar, promover y facilitar la participación. Precisamente para que sea cada vez más consciente de su papel protagonista y de la necesidad de superar una tradicional inercia pasiva para implicarse en la definición, gestión y seguimiento de las políticas públicas locales.

La legitimación de la Administración pública, lo sabemos bien, ha de basarse en los resultados, en la capacidad de la acción pública para satisfacer las nuevas demandas sociales, lo cual implica inevitablemente dar prioridad a la producción y entrega de bienes y servicios a los ciudadanos considerados como destinatarios, siempre desde el contexto del principio de legalidad y sabiendo que la función de la Administración se justifica en la medida en que sirve con objetividad los intereses generales. Perder de vista esta dimensión de servicio a la ciudadanía supone una clara 
quiebra del sentido y significación de la Administración pública. Por tanto, el rígido y uniforme organizativo que ha encorsetado y anulado muchas de las potencialidades de los entes locales, debe ser reformado, tal y como se hace en la ley que glosamos.

El Estado, de acuerdo con nuestra Constitución, se ha convertido en un Estado Social y Democrático de Derecho, superando anteriores concepciones basadas en una Administración de autoridad, limitadora de los derechos fundamentales y libertades públicas. Aparece también en la Constitución la introducción del principio de eficacia como elemento rector de la actividad administrativa, al que es necesario unir, como derivación del Estado Social, el mandato constitucional dirigido a los poderes públicos de remoción de los obstáculos que impidan al individuo y los grupos en que se integra disfrutar real y efectivamente de la libertad y de la igualdad. La eficacia debe ir siempre acompañada del servicio efectivo a los intereses generales. Si la eficacia se convierte en el criterio único de la acción administrativa, es muy fácil, y ejemplos hay, que se confundan los fines y los medios. Para que esto no ocurra, es menester abrir la eficacia a la realidad y, por ende, a la participación vecinal.

Insisto, los modelos políticos y administrativos deben construirse a partir del ciudadano y en función de sus necesidades colectivas, porque, como dispone nuestra Constitución, "la Administración sirve con objetividad los intereses generales y actúa de acuerdo con el principio de eficacia y descentralización, con sometimiento pleno a la Ley y al Derecho" (Artículo $113.1 \mathrm{CE}$ ). Además, la programación y ejecución del gasto público ha de responder a los principios de eficiencia y economía (Artículo 31.2 CE). Preceptos, los citados, que se aplican a todas las Administraciones, también por supuesto a la local, y que tienen una fuerte carga reformista y modernizadora.

Todo ello permite pensar en la necesidad de potenciar un clima de transformación permanente en los Gobiernos y Administraciones locales, en sentido de establecer las condiciones necesarias para su adaptación a unas circunstancias cambiantes de manera sistemática y cotidiana, aprovechando las opiniones de los ciudadanos sobre lo que, a su juicio, sería deseable.

La configuración del Estado social y democrático de derecho supone una nueva funcionalidad de los Gobiernos y Administraciones locales. En efecto, los Gobiernos locales, al gestionar los intereses colectivos, no tienen que imponerse frente a los ciudadanos. Más bien deben propiciar fórmulas

A \& C R. de Dir. Administrativo e Constitucional, Belo Horizonte, ano 4, n. 16, p. 29-64, abr./jun. 2004 
o medidas que impliquen la colaboración de la sociedad y, por tanto, de los vecinos en la elaboración de los criterios rectores que impulsen los intereses públicos locales. En otras palabras, el Gobierno y la Administración local ya no son dueños del interés público sino que están llamados, por su inserción en el Estado Social y Democrático de Derecho, a articular una adecuada intercomunicación con los agentes sociales locales para redefinir las políticas públicas. Quiere eso decir que los ciudadanos - los vecinos - no deben ser sólo sujetos pasivos de las potestades públicas, sino que deben aspirar a ser legítimos colaboradores y protagonistas de la propia Administración local para la gestión de los propios intereses que les afecten. Desde esta perspectiva puede entenderse mejor la función promocional de los Gobiernos y Administraciones locales del tiempo presente.

Conforme han ido avanzando los años noventa y entrábamos en el nuevo siglo, se ha ido perfilando con mayor claridad y se ha ido haciendo cada vez más explícita una idea que ha estado siempre presente de un modo u otro en el pensamiento democrático: el centro de la acción pública local reside en la dignidad de la persona, de cada vecina o de cada vecino.

La persona se constituye en el centro de la acción pública local. No la persona genérica o una universal naturaleza humana, sino la persona, cada individuo, cada vecino, revestido de sus peculiaridades irreductibles, de sus coordenadas vitales, existenciales, que lo convierten en algo irrepetible e intransferible, en persona.

Cada persona, cada vecino, es sujeto de una dignidad inalienable que se traduce en derechos también inalienables, los derechos humanos, que han ocupado, cada vez con mayor intensidad y extensión, la acción pública local.

En este contexto es donde se alumbran las nuevas políticas públicas locales que pretenden significar que es en la persona singular en donde se pone el foco de la atención pública, que son cada mujer y cada hombre, cada vecina y cada vecino.

Este cambio en el sentido de la vida pública y de sus instituciones, entre ellas las locales, se ha producido a la par que una reflexión sobre el sentido y las bases de la democracia misma. Esta reflexión ha venido obligada no sólo por los profundos cambios a los que venimos asistiendo en nuestro tiempo. Cambios de orden geoestratégico que han modificado parece que definitivamente el marco ideológico en que se venía desenvolviendo el orden político vigente para poblaciones muy numerosas. 
Cambios tecnológicos que han producido una variación sin precedentes en las posibilidades y vías de comunicación humana, y que han abierto expectativas increíbles hace muy poco tiempo. Cambios en la percepción de la realidad, en la conciencia de amplísimas capas de la población que permiten a algunos augurar, sin riesgo excesivo, que nos encontramos en las puerta de un cambio de civilización.

Es una reflexión obligada también por la insatisfacción que se aprecia en los países desarrollados de occidente ante los modos de vida, las expectativas existenciales, las vivencias personales de libertad y participación.

Y es una reflexión que nos conduce derechamente a replantearnos el sentido de la vida y del sistema democrático no para superarlo, sino para recuperarlo en su ser más genuino y despojarlo de las adherencias negativas con que determinados aspectos de las ideologías modernas lo han contaminado, contaminaciones que han estado en el origen de las lamentables experiencias totalitarias de este siglo, particularmente en Europa.

Recuperar el pulso democrático y fortalecerlo, significa entre otras cosas, recuperar para el Gobierno local los principios de su funcionalidad básica que se expresa adecuadamente - aunque no sólo - en aquellos derechos primarios sobre los que se asienta nuestra posibilidad de ser como hombres. Entre ellos el derecho a la vida, a la seguridad de nuestra existencia, el derecho a la salud.

Las claves, pues, reside en potenciar la dignidad del hombre, de la persona, de cada vecino. Me gusta esta expresión "cada vecino", para subrayar la condición de realidad concreta del sujeto a que me estoy refiriendo. Ese individuo - cada varón, cada mujer, en cualquier etapa de su desarrollo - es el portador de la dignidad entera de la humanidad. Escribo - aún a riesgo de ser malinterpretado - que en el hombre concreto, en su dignidad, en su ser personal, encontramos la condición de absoluto, o de referente de cuanto hay, acontece y se produce en el universo.

El pensamiento dinámico, nos lleva a comprender que la realidad — y más que ninguna la social, la humana; y especialmente la local — es dinámica, cambiante, abierta, y no sólo evolutiva, preñada de libertad. Por eso debemos superar la tendencia a definir estáticamente, o con un equilibrio puramente mecánico, lo real, que no resistiría tal encorsetamiento sin sufrir una grave tergiversación. Sobre la afirmación de su ser radical el hombre ha de desarrollar las virtualidades que allí se encierran, tanto

A \& C R. de Dir. Administrativo e Constitucional, Belo Horizonte, ano 4, n. 16, p. 29-64, abr./jun. 2004 
en lo que se refiere a su autodesarrollo personal como en lo relativo a la realización de su ser social. Pensar el hombre, la sociedad o la historia, a plazo fijo, con un punto final, como un proceso cuyo cierre vislumbramos, viene a ser negar el ser mismo del hombre. Quizás pueda afirmarse que ese ha sido el más grave error de la modernidad, o el de más graves y trágicas consecuencias. Por otra parte, el pensamiento complementario nos enseña que es posible superar las disyuntivas absolutas y permanentes a que nos condujo el racionalismo radical y nos anima a apreciar que en la realidad se puede dar unido - y de hecho se da - lo que me una mentalidad racional "matemática" — llamemosla así — nos exigía ver como opuestos. Por ejemplo, que lo público no es contradictorio con lo privado, sino compatible y complementario.

La acción pública local debe estar centrada en la persona, ya que es el desarrollo personal del ser humano el objetivo último de toda acción pública. Ese desarrollo no podrá producirse de un modo forzado, obligado, ni siquiera - apurando la expresión - podemos propiciarlo, porque propiamente sólo en la libertad se produce el crecimiento y la realización personal del propio proyecto, indisociable de nuestra condición de seres con intimidad, con libertad de conciencia. Pero debemos insistir en que la condición personal mira tanto a la dimensión individual como a la dimensión social del ser humano, en una hibridación portentosa que hace del hombre un sujeto de derechos.

La aproximación al ciudadano que plantéa la reforma actual se realiza adecuadamente como en su ámbito natural en la vida municipal. Se ha repetido hasta la saciedad que la Administración local es la Administración más próxima al ciudadano, y se ha repetido igualmente que la Administración debe acercarse al ciudadano, serle accesible. Como administrativista, no puedo hacer otra cosa que insistir en esas dos ideas, que sitúan la política municipal en su dimensión propia. Podríamos decir que la vida política se realiza primariamente, principalmente, en la política local. Es verdad que la espectacularidad corresponde a otros ámbitos, es verdad que las decisiones más graves pueden ser tomadas en otras instancias. Pero también es cierto que la frialdad jurídica y política del imperio de la ley toma acentos humanos en su aplicación. Alguien dijo "que dicten otros las leyes y que me dejen a mí los reglamentos”, queriendo significar que lo verdaderamente resolutivo, lo que alcanza la vida real está en la ordenación más próxima a la vida práctica. Podríamos traducir semejante valoración al campo de 
nuestro discurso afirmando que en la política municipal se produce - o nó - la humanización de la vida política.

Sin embargo debo destacar que tal proximidad no puede significar ahogamiento, encorsetamiento. La cercanía del Gobierno y de la Administración local al administrado no puede traducirse en un control rígido de su actividad y de su vida. Tal cercanía debe traducirse única y exclusivamente en la posibilidad de un servicio más real y efectivo. Si cercanía se tradujese en control opresivo, estaríamos socavando la condición básica y fundamental de toda vida política que pueda llamarse así, la libertad. Y la vida municipal debe entenderse antes que ninguna otra cosa como un ámbito de libertad. El utopismo, lo que podríamos llamar ingeniería social, un racionalismo desbordado tienen en la vida municipal el ámbito más tentador para la aplicación de sus recetas salvadoras y organizadoras. Tal tentación se ve agravada por la carga de "irresponsabilidad" de que se pueden ver aquejados ciertos políticos, derivada de la falta de una auténtica autonomía municipal.

Pero la pretensión de organizar la vida municipal desde arriba, contradice enteramente los supuestos sobre los que pretendemos asentar una vida política auténtica. Justamente es la libertad y la participación, un mayor grado de libertad y de participación lo que podemos considerar finalidad última de la acción pública local, y consecuentemente la tarea política, con todo lo que tenga de proyecto y de aportación de soluciones debe entenderse ante todo como un apoyo a las iniciativas sociales.

\section{Reformismo y apertura a la realidad}

El debate sobre la oportunidad de abordar una nueva Ley de régimen local que sustituyera a la vieja ley de 1985 es el típico de debate que suele plantearse cuando se trata de tomar decisiones en relación con la oportunidad o no de transformar radicalmente la realidad o de reformarla en lo que sea necesario. Está claro que desde los noventa del siglo pasado, existe un importante movimiento minicipalizador que, por las razones que sean, se ha concretado especialmente en los últimos años con diferentes reformas de la Ley de bases, de la Ley electoral o de la Ley Orgánica del Tribunal Constitucional entre otras. Son manifestaciones de lo que se ha venido en llamar Pacto Local que, en mi opinión, trata de reflejar que la cuestión local está por encima de las banderías partidistas y requiere de entendimiento y acuerdo, como es lógico.

A \& C R. de Dir. Administrativo e Constitucional, Belo Horizonte, ano 4, n. 16, p. 29-64, abr.jun. 2004 
Probablemente, como ocurrió con la reforma de la Ley 30/1992 de régimen jurídico de la Administración pública y del procedimiento administrativo común, se planteó la reforma, la transformación radical o, incluso, su sustitución por normas antiguas. La solución adoptada me parece adecuada: trabajar sobre lo que no funciona, admitiendo que puede haber aspectos de la Ley de 1985 que sí pueden resultar todavía los operativos. Como se lee en la exposición de motivos de la ley que comentamos, "a los dieciocho años de vigencia, se han puesto de manifiesto determinadas carencias y disfuncionalidades en determinados aspectos de la Ley de bases, lo cual unido a la deseable consolidación de nuestras Entidades locales, aconseja acometer una serie de modificaciones de ámbitos concretos". El reformismo es, pues, una manera determinada de plantear la mejora permanente de las condiciones de vida, en este caso de los vecinos, en que debe consistir esencialmente la acción de los Gobiernos y las Administraciones locales.

Podría interpretarse, ahora que las aventuras revolucionarias han perdido todo su prestigio en nuestro entorno, al menos en lo que se refiere a sus dimensiones no románticas, que todas las posturas políticas han adaptado su discurso y su proyecto político a los ritmos y las características de las políticas reformistas. Esto es un derivado necesario de la realidad social, económica y cultural de nuestras sociedades. Sin embargo cabría, bajo estas apariencias, la proyección de políticas que pretendieran un cambio desde la raíz pero realizado a plazos. El reformismo auténtico, según mi parecer, parte de una aceptación sustancial de la realidad presente. En nuestra sociedad atesoramos hoy valores muy profundos que deben ser enriquecidos con nuestra aportación. El legado de nuestros mayores, es el mejor que supieron y pudieron dejarnos. Bien como producto de su saber o de su ignorancia, bien de su iniciativa o de su pasividad, de su rebeldía o de su conformismo. Pero ellos, al igual que nosotros, se vieron movidos indudablemente por la intención de dejar a sus hijos la mejor herencia posible.

Pero esta aceptación no es pasiva ni resignada. Lejos de actitudes nostálgicas o inmovilistas, percibimos las estructuras humanas como un cuadro de luces y sombras. De ahí que la acción política se dirija a la consecución de mejoras reales, siempre reconociendo la limitación de su alcance. Una política que pretenda la mejora global y definitiva de las estructuras y las realidades humanas sólo puede ser producto de proyectos 
visionarios, despegados de la realidad de la gente. Las políticas reformistas son ambiciosas, porque son políticas de mejora, pero se hacen contando con las iniciativas de la gente - que es plural - y con el dinamismo social.

El reformismo tiene una virtualidad semejante a la de la virtud aristotélica, en cuanto se opone igualmente a las actitudes revolucionarias y a las inmovilistas. No se trata de una mezcla extraña o arbitraria de ambas actitudes, es, en cierto modo, una posición intermedia, pero sólo en cierto modo, porque no se alinea con ellas, no es un punto a medio en el trayecto entre una y otra.

La política inmovilista se caracteriza, como es obvio, por el proyecto de conservación de las estructuras sociales, económicas y culturales. Pero las políticas inmovilistas admiten, o incluso reclaman cambios. Ahora bien, los cambios que se hacen, se hacen - de acuerdo con aquella conocida expresión - para que todo siga igual. El reformismo, en cambio, aún aceptando la riqueza de lo recibido, no entraña una plena conformidad, de ahí que desee mejorarlo efectivamente, no haciendo cambios para ganar una mayor estabilidad, sino haciendo cambios que representen o conduzcan a una mejora auténtica - por consiguiente, a una reforma real - de las estructuras sociales, o dicho en otros términos, a una mayor libertad, solidaridad y participación de los ciudadanos.

La política revolucionaria, pretende subvertir el orden establecido. Es decir, darle la vuelta, porque nada hay de aprovechable en la situación presente, hasta el punto que se interpreta que toda reforma es cambio aparente, es continuismo. Por eso puede considerarse que las políticas revolucionarias, aun las de apariencia reformista, parten de un supuesto radicalmente falso, el de la inutilidad plena o la perversión completa de lo recibido. Afirmar las injusticias, aun las graves y universales que afectan a los sistemas sociales imperantes, no puede conducir a negar cualquier atisbo de justicia en ellos, y menos todavía cualquier posibilidad de justicia. Aquí radica una de las graves equivocaciones del análisis marxista, que si bien presenta la brillantez y coherencia global heredada de los sistemas racionalistas, conduce igualmente, en virtud de su lógica interna a la necesidad de una revolución absoluta - nunca mejor definida que en los términos marxistas - y por tanto a la destrucción radical, en todas sus facetas, de cualquier sistema vigente.

Hoy parece cada vez más evidente la afirmación que el camino del progreso es la vía de las reformas. Está abocada al fracaso la titánica — e imposible - empresa de construir la realidad humana desde cero,

A \& C R. de Dir. Administrativo e Constitucional, Belo Horizonte, ano 4, n. 16, p. 29-64, abr./jun. 2004 
arrasando todo lo recibido, como los utopismos políticos de toda clase han pretendido. Las políticas de reformas suponen el reconocimiento de la complejidad de lo real, y en igual medida la constatación de la limitación humana en el diseño y en la proyección de la propia existencia.

En realidad, durante estos años, todos los Gobiernos se han planteado cómo mejorar la eficacia administrativa, como introducir reformas que modernicen la Administración local.

La sociedad está inmersa en un profundo y continuo cambio en prácticamente todos los campos: social, económico, político y tecnológico, lo que va a originar un constante esfuerzo de adaptación a la realidad por parte de las Administraciones públicas: la aparición de fenómenos como el de la inmigración, el continuo desarrollo de nuevas técnicas audiovisuales o remodelaciones estatales como la creación de las Autonomías en España obligan a respuestas en un plazo breve de tiempo y a profundas reestructuraciones en la Administración forzándolas a un continuo proceso de mejora y adaptación.

En el marco de la reforma administrativa actual, se tiene claro que los ciudadanos, la gente, los vecinos, son los auténticos dueños de la Administración pública, y se es consciente de que también la Constitución es el marco para la acción pública. Por eso, a partir de las elecciones de 1996 se comenzó un proceso de reformas presidido por la idea de construir una Administración que piense más en la gente y que sea más sensible a los derechos humanos de los ciudadanos en un contexto de mayor calidad en el ejercicio de los servicios públicos.

La constitución española de 1978, como ya he señalado, define la Administración como una organización que sirve con objetividad intereses generales (Artículo 103.1 CE), la Carta Magna nos recuerda que las reformas administrativas, así se está haciendo, deben levantarse en función de las personas y no en función de los intereses burocráticos. ¿Por qué?. Porque, como también señala la Constitución, corresponde a los poderes públicos - artículo 9.2 CE — promover las condiciones para que la libertad y la igualdad del individuo y de los grupos en que se integra sean reales y efectivas; remover los obstáculos que impiden o dificulten su plenitud y facilitar la participación de todos los ciudadanos en la vida política, económica, cultural y social.

La ingente tarea que supone este aspecto de la vida pública requiere profundizar en las ideas que lo sostiene: asegurar las libertades reales de la gente. En este aspecto el Gobierno y la Administración local aparecen 
como uno de los elementos clave para asegurar que las aspiraciones de los españoles puedan hacerse realidad, por lo tanto: ni nunca podrá ser un aparato que se cierra a la creatividad, o la impida con cualquier tipo de trabas, ni tampoco podrá dejar, especialmente a los más débiles, al arbitrio de intereses egoístas.

El modelo de las nuevas políticas en relación con la Administración pública, apuesta por la libertad, que es apostar por la sociedad, por confiar en el hombre, por confiar en la capacidad, en las energías, en la creatividad de las personas que ha tenido amplia cabida en la historia y no solamente no tiene por qué dejar de tenerla: es el momento histórico de potenciarla.

El pensamiento compatible, permite que al tiempo que se hace una política de impulso de la sociedad civil, que no haya compuertas que limiten una acción de la Administración que asegure la libertad de disfrutar, por ejemplo, de una justa y digna jubilación de nuestros mayores, que limiten la libertad de disponer de un sistema de salud para todos, que recorten la libertad de que todos tengan acceso a la educación en todos sus niveles, o acceso a un puesto de trabajo, o sencillamente a disfrutar de la paz.

Por eso, para mi, el Gobierno y la Administración local deben ser un entorno de entendimiento, y un marco de humanización de la realidad que fomente el objetivo constitucional central: "la dignidad de la persona, los derechos inviolables que le son inherentes, el libre desarrollo de la personalidad, el respeto a la ley y a los derechos de los demás" (Artículo 10.1 CE).

Por tanto, el aparato administrativo local debe promover las condiciones para que todos los vecinos, sin excepción, podamos ejercer con mayor calidad nuestras libertades, teniendo también presente que la Administración también debe estar próxima, cercana a la gente en un ambiente de real descentralización (Artículo 103.1 CE) y teniendo presente que la programación y ejecución del gasto público debe responder a los criterios de eficiencia y eficacia (Artículo 31.2 CE).

Pues bien, las reformas administrativas puestas en marcha se encaminan en esta dirección. Es el caso de la redefinición de la Administración periférica del Estado como consecuencia de la LOFAGE Ley de Organización, Funcionamiento de la Administración General del Estado - con un contrastado ahorro en el gasto público. Es el supuesto del Pacto Local que apuesta definitivamente por el reforzamiento de los entes locales y por la autonomía local en un contexto de equilibrio de los

A \& C R. de Dir. Administrativo e Constitucional, Belo Horizonte, ano 4, n. 16, p. 29-64, abr./jun. 2004 
diferentes poderes territoriales. Es el caso de la consolidación y estabilidad del Estado autonómico desde el acuerdo y la búsqueda del pacto. Es el caso de la reforma del procedimiento administrativo que por fin instaura un verdadero sistema de silencio administrativo positivo y un acortamiento real de los plazos que tiene la Administración para resolver los expedientes administrativos. Es el caso de la recepción del principio de lealtad institucional, de confianza legítima, y de transparencia como elementos vertebradores de la reforma administrativa. Y es el caso de la ley que ahora comentamos.

Por ello, una Administración Pública como la local que se ajuste adecuadamente a las demandas democráticas ha de responder a una rica gama de criterios que podríamos calificar de internos, por cuanto miran a su propia articulación interior, a los procesos de tramitación, a su transparencia, a la claridad y simplificación de sus estructuras, a la objetividad de su actuación, etc. Pero por encima de todos los de esta índole o, más bien, dotándolos de sentido, debe prevalecer la finalidad de servicio al ciudadano a que vengo haciendo alusión.

No puedo dejar de subrayar insistentemente la centralidad del individuo en mi entendimiento de lo que deben ser los intereses generales. El individuo real, la persona, el vecino, con el cúmulo de circunstancias que lo acompañan, en su entorno social, es el auténtico sujeto de los derechos y libertades que en la Constitución proclamamos. A ese hombre, a esa mujer, con su determinada edad, su grado de cultura y de formación, mayor o menor, con su procedencia concreta y sus intereses particulares, propios, legítimos, es a quien los gobiernos y las Administraciones locales sirven. Al servicio de esa persona concreta el aparato administrativo debe promover las condiciones para que ejerza con la mayor calidad y hondura sus libertades.

\section{Sobre la participación}

El principio de participación es un criterio constitucional (Artículos 9 y 23) central del Estado democrático. Aunque se discute sobre si es una verdadera directriz de alcance general, pienso que sí es un vector general que debe inspirar la acción pública, siendo, en cada momento el legislador quién deberá modular su alcance y operatividad. La participación la entiendo no sólo como un objetivo que debe conseguirse: mayores posibilidades de participación de los ciudadanos en la cosa pública,

A \& C R. de Dir. Administrativo e Constitucional, Belo Horizonte, ano 4, n. 16, p. 29-64, abr./jun. 2004 
mayores cotas de participación de hecho, libremente asumida, en los asuntos públicos. La participación significa también, un método político. En el futuro inmediato, según la apreciación de muchos y salvando el esquematismo, se dirimirá la vida política entre la convocatoria de la ciudadanía a una participación cada vez más activa y responsable en las cosas de todos y un individualismo escapista avalado por políticas demagógicas que pretenderán un blando conformismo social. Pero entender la participación como método significa que es necesario llamar a la ciudadanía a la participación, y de hecho posibilitándola, haciendo real el método del entendimiento, entendiéndose con la gente, con los vecinos.

Pienso que el método del entendimiento trae consigo el ocaso de una ficción y la denuncia de una abdicación. Supone que la confrontación no es lo sustantivo del procedimiento democrático, ese lugar le corresponde al diálogo. La confrontación es un momento del diálogo, como el consenso, la transacción, el acuerdo, la negociación, el pacto o la refutación. Todos son pasajes, circunstancias, de un fluido que tiene como meta de su discurso el bien social, que es el bien de la gente, de las personas, de los individuos de carne y hueso.

A la habilidad, a la perspicacia, a la sabiduría, y a la prudencia política les corresponde la regulación de los ritmos e intensidades de ese proceso, pero queda como coordenada la necesidad de entendimiento decir, explicar, aclarar, razonar, convencer... - el carácter irrenunciable de este método, si es que queremos hacer una política de sustancia democrática.

Hablar de la participación como método es hablar de la apertura del ente local que la quiere practicar, hacia la sociedad. Una organización pública cerrada, vuelta sobre sí misma, no puede pretender captar, representar o servir los intereses propios de la gente, de los vecinos. La primera condición de esa apertura es una actitud, una disposición, alejada de la suficiencia y de la prepotencia, propias tanto de las formulaciones ideológicas como de las tecnocráticas. Pero las actitudes y las disposiciones necesitan instrumentarse, traducirse en procesos y en instrumentos que las hagan reales. Y la primera instrumentación que exige una disposición abierta es la comunicativa, la comunicación.

Para ello es necesaria una voluntad de recibir, de tener la sensibilidad suficiente para captar las preocupaciones e intereses de la sociedad en sus diversos sectores y grupos, en los individuos y colectividades que la integran.

A \& C R. de Dir. Administrativo e Constitucional, Belo Horizonte, ano 4, n. 16, p. 29-64, abr./jun. 2004 
Pero no se trata simplemente de apreciaciones globales, de percepciones intuitivas, ni siquiera simplemente de estudios o conclusiones sociométricas. Todos esos elementos y otros posibles son recomendables y hasta precisos, pero la conexión real con los ciudadanos, con los vecinos, con la gente, exige diálogo real. Y diálogo real significa interlocutores reales, concretos, que son los que encarnan las preocupaciones y las ilusiones concretas, las reales, las que pretendemos servir.

En la libre participación encontramos un elemento central de la vida individual y social de los hombres y de las mujeres, un elemento que contribuye de forma inequívoca a definir el espacio público de que tratamos, que lo que hace es poner en el foco de su atención a las mismas personas.

La participación, en efecto, supone el reconocimiento de la dimensión social del individuo, la constatación de que sus intereses, sus aspiraciones, sus preocupaciones trascienden el ámbito individual o familiar y se extienden a toda la sociedad en su conjunto. Sólo un ser absolutamente deshumanizado sería capaz de buscar con absoluta exclusividad el interés individual. La universalidad de sentimientos tan básicos como la compasión, la rebelión ante la injusticia, o el carácter comunicativo de la alegría, por ejemplo, demuestran esta disposición del ser humano, derivada de su propia condición y constitución social.

Afirmar por tanto la participación como objetivo político de los Entes locales tiene la implicación de afirmar que el hombre, cada individuo, debe ser dueño de sí mismo, y no ver reducido el campo de su soberanía personal al ámbito de su intimidad. Una vida humana más rica, de mayor plenitud, exige de modo irrenunciable una participación real en todas las dimensiones de la vida social, también en la política.

Sin embargo, hay que resaltar que la vida humana, la de cada hombre, no se diluye en el todo social. Si resulta monstruoso un individuo movido por la absoluta exclusividad de sus intereses particulares, lo que resulta inimaginable e inconcebible es un individuo capaz de vivir exclusivamente en la esfera de lo colectivo, sin referencia alguna a su identidad personal, es decir, alienado, ajeno enteramente a su realidad individual.

Por este motivo la participación como un absoluto, tal como se pretende desde algunas concepciones organicistas de la sociedad, no es posible. De ahí que me resulte preferible hablar de libre participación. Porque la referencia a la libertad, además de centrarnos de nuevo en la 
condición personal del individuo, nos remite a una condición irrenunciable de su participación, su carácter libre, pues sin libertad no hay participa ción. La participación no es un suceso, ni un proceso mecánico, ni una fórmula para la organización de la vida social. La participación, aunque sea también todo eso, es más: significa la integración del individuo en la vida social, la dimensión activa de su presencia en la sociedad, la posibilidad de desarrollo de las dimensiones sociales del individuo, el protagonismo singularizado de todos los hombres y mujeres.

Aunque los factores socioeconómicos, por ejemplo, sean importantísimos para la cohesión social, ésta no se consigue solo con ellos, como puedan pensar los tecnócratas y algunos socialistas. Aunque los procedimientos electorales y consultivos sean llave para la vida democrática, ésta no tiene plenitud por el solo hecho de aplicarlos, como pueden pensar algunos liberales. La clave de la cohesión social, la clave de la vida democrática está en la participación de todos los ciudadanos en los asuntos públicos.

En este sentido la participación no puede regularse sólo con decretos ni únicamente con reglamentos. Sólo hay real participación — insisto — si hay participación libre. De la misma manera que la solidaridad no puede ser obligada. Esta relación de semejanza entre participación y solida ridad no es casual, por cuanto un modo efectivo de solidaridad, tal vez uno de los más efectivos, aunque no sea el más espectacular, sea la participación, entendida como la preocupación eficaz por los asuntos públicos, en cuanto son de todos y van más allá de nuestros exclusivos intereses individuales.

Ahora bien, al calificar la participación como libre, quiero referirme no sólo a que es optativa sino también a que, en los infinitos aspectos y modos que la participación es posible, es cada vecino quien libremente regula la intensidad, la duración, el campo y la extensión de su participación. En este sentido, la participación - al igual que la solidaridad — es resultado de una opción, de un compromiso, que tiene una clara dimensión ética, ya que supone la asunción del supuesto de que el bien de todos los demás es parte sustantiva del bien propio. Pero aquí nos encontramos en el terreno de los principios, en el que nadie puede ser impelido ni obligado.

De este modo, y aunque sea provisionalmente, cerramos el círculo, en cuanto que se vuelve la atención a la persona concreta, enfrentada a su quehacer público en toda su dimensión social. En esto parece consistir la concepción que se preconiza desde los nuevos espacios: son los hombres y mujeres singulares y concretos quienes reclaman nuestra atención, y para 
ellos es para quien reclamamos el protagonismo. Y por esto mismo la libre participación en la vida de la sociedad, en sus diversas dimensiones - económica, social, cultural, política - puede erigirse como el objetivo político último, de los Entes locales, ya que una participación plenamente realizada significa la plenitud de la democracia.

La doble consideración de la participación, como objetivo y como método, podemos, pues, considerarla otro rasgo que define los nuevos espacios a que se abren en el terreno político de las democracias europeas. Constituye también otro paso - o es una consecuencia - en el proceso de desideologización de la vida política que parece vivirse en este momento. Además, me parece que es el inicio de una respuesta a la sentida necesidad de profundizar y reavivar la vida democrática. No obstante una cuestión sigue en pie, la de la articulación concreta, objetiva, real, de esa participación, tanto en el método como en el objetivo.

Suponer que la participación es un objetivo que sólo se puede alcanzar al final de un proceso de transformación política, sería caer en uno de los errores fundamentales del dogmatismo político implícito en las ideologías. El socialismo con la colectivización de los medios de producción; el fascismo con la nacionalización de la vida social, económica, cultural y política; el liberalismo doctrinario - aunque aquí serían necesarias ciertas matizaciones - con la libertad absoluta de mercado, pretenden alcanzar una libertad auténtica que despeje los sucedáneos presentes de la libertad, que no son sino espejismos, engañiflas o cadenas que nos sujetan.

La libertad y la participación que se presentan como objetivos no son de naturaleza diferente a la libertad y participación de cada ciudadano. Si la libertad y la participación de que gozamos hoy en las sociedades democráticas occidentales no fueran reales y auténticas, poco importaría prescindir de ellas - como desde ciertas posiciones ideológicas se puede afirmar —, pero no es así. La raíz de la libertad está en los hombres y mujeres concretos, singulares, no en la vida y en el ser nacional, ni en la liberación de una clase social a la que se reduce toda la sociedad.

Por eso precisamente, porque no es necesario liberar una clase ni una nación para que haya en algún grado libertad auténtica, es por lo que se puede afirmar la autenticidad de la libertad — mejorable, pero auténtica - que en distinta forma y medida todos hemos alcanzado. Proponer la participación como objetivo de los Entes locales no significa otra cosa, pues, que desde el estadio presente de libertad y de participación caminar

A \& C R. de Dir. Administrativo e Constitucional, Belo Horizonte, ano 4, n. 16, p. 29-64, abr./jun. 2004 
hacia cotas y formas de mayor alcance y profundidad que las actuales, pero contando con lo que tenemos y sin ponerlo frívolamente en juego.

Pretender recorrer este camino sin contar con las personas para quienes se reivindica el protagonismo participativo sería contradictorio, se incurriría en una incoherencia inaceptable. Y el rigor y la coherencia son valores de primer orden, cuya pérdida traería consigo la pérdida también de los valores de equilibrio y moderación que nos sitúan en el centro. Se trata, pues, de poner en juego todas las potenciales formas de participación que en este momento enriquecen los tejidos de nuestra sociedad, como condición metodológica para alcanzar no sólo grados de participación más altos, sino también nuevos modos de participación.

Los Entes locales deben, así, la permeabilidad de los que se desarrollan como organizaciones abiertas y sensibles a los intereses reales de la sociedad, que son los intereses legítimos de sus integrantes, tomados bien individualmente bien en sus múltiples y variadas dimensiones asociativas, bien en las diversas agrupaciones producto del dinamismo social.

Un Ente local quiere decir una Corporación local capaz de ponerse en sintonía con los grupos, sectores, segmentos sociales, y capaz, por tanto, de ejercer con eficacia y reconocimiento su representación.

Hablar de participación es hablar también de cooperación. La participación es siempre "participación con”. De ahí que el protagonismo de cada individuo es en realidad coprotagonismo, que se traduce necesariamente en la conjugación de dos conceptos claves para la articulación de una política centrada en la persona: autonomía e integración, las dos patas sobre las que se aplica el principio de subsidiariedad. En ningún ámbito de la vida política debe ser absorbido por instancias superiores lo que las inferiores puedan realizar con eficacia y justicia.

Estos dos conceptos, por otra parte, están en correspondencia con la doble dimensión de la persona, la individual y la social, la de su intimidad y la de su exterioridad. Insistimos en que se trata de la doble dimensión de un mismo individuo, no de dos realidades diferenciadas y distantes, que puedan tener una atención diversa. Más bien, la una nunca actúa ni se entiende adecuadamente sin la otra.

Si la libertad - en el plano moral - es en última instancia una consecución, un logro personal; si la participación, el protagonismo en la vida pública — sea por el procedimiento y en el ámbito que sea sólo puede ser consecuencia de una opción personalmente realizada; 
la solidaridad es constitutivamente una acción libre, sólo puede comprenderse como un acto de libre participación.

La diversificación de intereses, impulsados por un clima de participación y compromiso cada vez mayores con los asuntos públicos, sobre todo - aunque no exclusivamente - , por parte de los jóvenes, ha culminado en el establecimiento de un denso tejido asociativo, con intereses, sensibilidades e incluso planteamientos políticos diversos. En ese tejido deben buscarse - sin exclusiones preestablecidas - a los interlocutores: asociaciones y colegios profesionales, asociaciones de padres de alumnos, asociaciones de amas de casa, de mujeres, grupos juveniles; entidades deportivas y culturales, organizaciones no gubernamentales, grupos, entidades y asociaciones de la tercera edad, asociaciones parroquiales, grupos y asociaciones ecologistas, sectores industriales y empresariales, consumidores, asociaciones y movimientos vecinales, entidades educativas, órganos de la administración particularmente dirigidos a la atención al público; comisiones de fiestas, medios de comunicación, sociedades gastronómicas, instituciones de recreo y tiempo libre, sociedades de caza y pesca; etc., etc., etc. La capacidad para establecer un diálogo con el más amplio número de representantes sociales será un indicativo de su apertura real a la sociedad.

En ese diálogo no debe olvidarse el objetivo principal que se persigue. No se trata de convencer, ni de transmitir, ni de comunicar algo, sino ante todo y sobre todo, en primer lugar, de escuchar. Y debe recordarse que en diálogo escuchar no comporta una disposición pasiva, sino al contrario, es una disposición activa, indagatoria, que busca el alcance de las palabras del interlocutor, comprender su manera de percibir la realidad, la conformación de sus preocupaciones y la proyección de sus ilusiones y objetivos. Por eso el punto de partida es la correcta disposición de apertura. Sin ella el diálogo será aparente, sólo oiremos lo que queremos oír e interpretaremos de modo sesgado lo que se nos dice. La pretensión de centrarse en los intereses de la gente será ilusoria.

Ese diálogo debe caracterizarse además por su flexibilidad. Es decir, no se trata de un intercambio rígido y formalista; no es una encuesta, está abierto, y han de ponerse en juego los factores personales y ambientales necesarios para hacerlo más confiado y fructífero. En ese mismo sentido ha de tenerse en cuenta el talante personal del interlocutor y contar también con el propio, para que la condición de los interlocutores no sea 
un elemento de distorsión en la comunicación. El diálogo debe conducirse sin limitación en los temas. También interesa conocer, cuando sea el caso el descontento que producimos, a quien y por qué. Y en medio de la multitud de propuestas de solución que se darán, habrá que resaltar que interesa considerarlas todas, pero de modo muy especial las que tengan como rasgo el equilibrio propio del centro, es decir, las que toman en consideración a todos los sectores afectados por el problema que se trate o la meta que se persiga, y no sólo al propio.

El diagnóstico que se pretende constituye un ejercicio público real, por su objetivo - comprender las aspiraciones de nuestra sociedad en su complejidad estructural - , por el procedimiento - comunicación —, por los juicios de valor que lleva aparejados - en cuanto a urgencia, importancia y precedencia de las cuestiones que se planteen - Por otra parte, sustanciar un diálogo en estas condiciones comporta una mejora ética del político, porque sólo con un ejercicio de sinceridad y autenticidad podrá ponerse en el lugar de la gente a la que sirve.

No hay mejor modo de transmitir a la gente la importancia y la necesidad de su participación en los asuntos públicos, y el enriquecimiento político personal y social que comporta su ejercicio, que practicarla efectivamente.

\section{La OCDE y la participación}

Está claro que hoy la gente expresa sus necesidades colectivas e inquietudes públicas en el marco de unas sociedades cada vez más diversas, más plurales, más complejas y más fragmentadas. Y, por otra parte, no se debe olvidar que hoy, en términos generales, los ciudadanos disponen de más conocimientos que antes, lo cual plantea nuevas oportunidades y nuevas expectativas. Hoy, el ritmo de los cambios es permanente por lo que los Gobiernos y las Administraciones no pueden dormirse a partir de un cuadro fijo de soluciones. Hoy, es necesario que los Gobiernos y las Administraciones dispongan del hábito de la escucha continua de las siempre nuevas inquietudes sociales. Pero no solo es suficiente la tarea de la escucha o la consulta. Lo decisivo es adelantarse en la determinación y selección de políticas y, así, proponerlas en el momento adecuado. De ahí, pues, la necesidad de facilitar y promover cauces amplios para la participación.

Pues bien, exposición de la ley de modernización del Gobierno

A \& C R. de Dir. Administrativo e Constitucional, Belo Horizonte, ano 4, n. 16, p. 29-64, abr.jun. 2004 
local señala que es necesario "evitar el alejamiento de los ciudadanos de la vida pública”. Uno de los objetivos de las reformas de la gestión pública en marcha en tantos países del mundo es precisamente restablecer la confianza de los ciudadanos en la Administración y en el Gobierno. Es esta una cuestión compleja que no se resuelve sólo cuantitativamente sino que tiene una dimensión cualitativa esencial, pues el ejemplo de políticos y altos funcionarios es capital. Sobre todo, en lo que se refiere a la vertiente ética y en lo atinente a la cercanía de los responsables públicos en relación con las necesidades reales de la ciudadanía. En este sentido, además, como señala un informe del Comité de Gestión Pública de la OCDE (PUMA, Junio de 2001) que ahora glosamos, los Gobiernos deben adoptar un enfoque proactivo para la resolución de los problemas, anticipándose a las necesidades colectivas y mudando, cuando sea necesario, la forma de negociar para resolver los asuntos de la ciudadanía. Es necesaria, pues, más democracia, más transparencia y más facilitar la libre elección de servicios a los ciudadanos.

El documento de la OCDE también nos advierte sobre la necesidad de que los Gobiernos comuniquen bien sus mensajes a los ciudadanos. Es más, el Gobierno, según la OCDE, debe aprovechar las oportunidades para comunicarse personalmente con los ciudadanos a través de las nuevas tecnologías y los nuevos foros de comunicación.

Como es sabido, los regímenes democráticos son regímenes de opinión. Los valores de transparencia, pluralidad e independencia informativa son componentes estructurales de las nuevas políticas. Las llamadas a la libertad, a la participación, a la cooperación, a la auto nomía de los ciudadanos, de los individuos, como objetivos últimos de la acción política, serían vanas si no se estableciesen sobre el marco previo de las libertades formales que configuran los mecanismos o espacios democráticos de participación y libertad, y carecerían de sentido si no se fundamentasen en una información transparente, veraz, plural e independiente.

La madurez democrática de una sociedad, pasa necesariamente por la riqueza y pluralidad informativa. Las nuevas políticas se caracterizan por su estricta neutralidad informativa en lo que a condicionamiento de la independencia de los medios se refiere, y por la defensa y promoción de la pluralidad informativa real, velando por el mantenimiento de las condiciones de competencia. Sólo una sociedad informada puede

A \& C R. de Dir. Administrativo e Constitucional, Belo Horizonte, ano 4, n. 16, p. 29-64, abr./jun. 2004 
ser libre. Y cuando en los tiempos presentes el acceso y el control de la información se perfila del modo más claro como un instrumento de poder, la democratización de la vida política exige el libre acceso a fuentes plurales de información.

Pero en otro orden de cosas, las nuevas políticas deben desempeñar una acción positiva de transmisión a la opinión pública, a los ciudadanos, de su discurso político, asumiendo una función pedagógica, como medio de enriquecer el discurso democrático. Cuando el escenario político ha estado dominado por los discursos de carácter ideológico, en muchas ocasiones reduccionistas, y siempre concibiendo las ideas prioritariamente como instrumentos de lucha política, desde las nuevas políticas deben concebirse las ideas como instrumentos para una mejor comprensión de nuestra propia realidad. Algunas reformas, precisamente las más profundas, las que afectan a la cultura democrática, sólo son posibles desde este presupuesto. Cierto que este modo de abordar la cuestión tiene una indudable dimensión política, ni más ni menos que la de promover condiciones que permitan a los ciudadanos un ejercicio más profundo y auténtico de su libertad.

Las nuevas políticas traen consigo una particular exigencia de pedagogía política. En el desarrollo de sus políticas, los Gobiernos deben atender de modo muy particular a la comunicación con el entorno social, con toda la sociedad.

No se trata de una labor de adoctrinamiento, de una conversión ideológica, sino de transmitir los valores de que aquí venimos tratando. El respeto a las posiciones ideológicas, a los valores que individualmente cada ciudadano defiende, debe conjugarse con la insistencia en la llamada a abrirse a la realidad de las cosas, y a su complejidad, haciendo ver que las soluciones simplistas no son soluciones, que la prudencia es una buena guía en las decisiones políticas, y que esta no está reñida - antes al contrario - con las metas sociales ambiciosas; que importa más el trabajo serio y consolidado que los gestos superficiales y sin fundamento, que bajo la apariencia de progreso esconden un progresivo deterioro de la vida económica y social e incluso de la ética, que nunca tardará demasiado en ponerse en evidencia.

Es cierto, como señala el documento de la OCDE que el papel del Gobierno en una sociedad en permanente transformación también está sometido a profundos cambios. Es cierto que hay evidentes pérdidas de situaciones de monopolio. Es cierto que la globalización es una realidad 
que trae consigo una mayor interdependencia. Todo esto es cierto. Pero no lo es menos que, en este contexto, el Gobierno sigue siendo la única instancia pública que puede seguir promoviendo el libre ejercicio de los derechos fundamentales para todos y cada uno de los ciudadanos. Y, para ello, es necesario mentalidad abierta, metodología del entendimiento y sensibilidad social.

En otro orden de cuestiones, la OCDE, en el documento que ahora glosamos, se plantea las lecciones aprendidas de la reforma de la gestión pública. Y una de las lecciones más importantes que nos ofrece la experiencia es que es necesario conocer mejor las necesidades colectivas de los ciudadanos. Además, resulta que hoy en día la mayor parte de la reforma de la gestión pública no se desarrolla con la deseable anticipación, sino como respuesta a las crisis que surgen cuando estas necesidades no han sido satisfechas. Por eso, en este punto, el desafío de los Gobiernos es el alejamiento de las versiones oportunistas, y orientarse hacia reformas de mayor calado estratégico, con perspectivas de más largo alcance y estableciendo tácticas para obtener resultados a la vez que comunicando sus ideas y los resultados obtenidos. Es necesario, pues, elegir objetivos, y medir los resultados, pero sin que la eficacia elimine la dimensión social que necesariamente deben caracterizar a los Gobiernos.

Además de consultar con frecuencia a los ciudadanos, es necesario contar con el apoyo de los ciudadanos sobre los intereses y objetivos de la reforma de la gestión pública. Obtener el apoyo de la ciudadanía para la reforma, dice la OCDE, significa no sólo escoger una agenda que interese a la gente, sino también ganar la confianza de los ciudadanos para que las acciones del Gobierno lleven a resultados positivos.

Aplicando lo que he señalado sobre opinión pública y pedagogía política al tema de la reforma y modernización administrativa, habría que señalar que comunicar la necesidad de la reforma supone transmitir los valores y metas que presiden el entero proceso de la reforma. La transmisión de los valores ayuda a crear una conexión razonable con la gente y a superar las versiones burocráticas que, en ocasiones, caracterizan la actuación de los propios funcionarios. Transmitir y comunicar el proceso de la reforma o de la modernización ayuda igualmente a los funcionarios a entender su papel en el programa.

Para la comunicación, es necesario insistir en que debe utilizarse un lenguaje sencillo y llano que rehuya todos los términos excesivamente 
técnicos. El mensaje de la reforma, como dice la OCDE, debe ser claro, indicando los costes potenciales y los inconvenientes, sin excederse en las promesas y centrándose en los logros obtenidos.

\section{El espacio local: el espacio de la participación}

Los Estados compuestos como el español se caracterizan, entre otras cosas, por la existencia de determinados espacios territoriales que disfrutan de autogobierno y autoadministración en un marco de integración, cooperación y lealtad institucional. El gobierno de España, los gobiernos de las Comunidades Autónomas, y los gobiernos de los diferentes Entes locales son gobiernos democráticos, elegidos por los ciudadanos, que se caracterizan por su autonomía para la realización de políticas públicas propias en el ámbito de sus respectivas competencias.

Los gobiernos se legitiman, podríamos decir, en la medida en que asumen efectivamente un compromiso creciente con los problemas reales de la gente. Siendo esto así, como lo es, no es menos cierto que cada vez, según la común opinión de politólogos y administrativistas, los Gobiernos nacionales, y en cierta medida también los regionales o autonómicos, cada vez deben circunscribir sus políticas a la orientación general, a la planificación estratégica o, si se quiere, al establecimiento de las bases, o el común denominador, que hagan posible la igualdad en las condiciones básicas para el ejercicio de los derechos humanos por todos los españoles, con independencia del lugar de España en que residan.

Por otra parte, si bien, las Comunidades Autónomas están llamadas, por su inserción en el esquema descentralizador, a elaborar igualmente políticas públicas de ámbito supramunicipal, no debemos olvidar que deben, y así ocurre afortunadamente, dedicar una parte sustancial de sus recursos materiales y medios humanos a actividades de pura gestión o ejecución. Pero es, sin embargo, el espacio local el espacio de la gestión por autonomasia. Además, por su cercanía a la gente, el espacio local se nos presenta también como un espacio muy adecuado para las experiencias participativas, así como para las reformas e innovaciones de determinadas políticas públicas. En este sentido, hasta podría decirse sin exageración alguna, que el espacio local es un permanente laboratorio democrático en el que el pluralismo y la participación, si hay voluntad política, resplandecerán permanentemente. Y no digamos la posibilidad de hacer buena esa reflexión tan atinada de que la Administración pública, en una democracia, es de la

A \& C R. de Dir. Administrativo e Constitucional, Belo Horizonte, ano 4, n. 16, p. 29-64, abr./jun. 2004 
gente, de los vecinos.

A ello ayuda también la revalorización operativa de la vida local en el espacio europeo, en el cual se comprueba el paulatino aumento de la actuación externa de los entes locales, dirigida a los más diversos sectores materiales, con el objetivo de mejorar la calidad de vida. Las funciones que, en el ámbito europeo, son realizadas por los Entes locales afectan a materias tales como la seguridad pública, la prestación de nuevos servicios asistenciales, funciones de ordenación y planificación urbanística, de promoción y dinamización social, fijación de programas de medio ambiente, promoción económica del territorio y fomento de la ocupación. De lo que se trata, en definitiva, como ha señalado el Presidente del Gobierno José María AZNAR, es de la necesidad de que, en un país tan descentralizado como España en favor de Autonomías y Ayuntamientos, se alcancen mejores equilibrios territoriales, para lo que se considera razonable y conveniente la consecución del pacto local, una vez que, como es fácilmente comprobable, el Estado Autonómico ha entrado en fase de consolidación.

Hay un aspecto de la Carta Europea de la Autonomía local de interés para el tema que nos ocupa. Me refiero a la conexión de la autonomía local con el principio democrático. En efecto, el Preámbulo de la carta señala a los entes locales como un ámbito privilegiado de la participación de los ciudadanos en la gestión de los asuntos públicos como cuna de la democracia: "La defensa y el fortalecimiento de la autonomía local en los diferentes países de Europa representan una contribución esencial en la construcción de una Europa basada en los principios de democracia y descentralización".

Esta reflexión parte esencialmente del principio democrático, desde la perspectiva de posibilitar que los ciudadanos se sientan representados con la máxima intensidad posible en las decisiones que les afectan. De aquí la preferencia por la autoridad representativa más próxima, que sólo debe quedar desplazada cuando los efectos benéficos de una autoridad superior compense la pérdida de integración democrática.

El local es el nivel de gobierno en relación al cual los ciudadanos expresan mayor interés político, lo cual no es extraño si se piensa que son las instituciones encargadas de velar por los intereses y los problemas del entorno más inmediato de los ciudadanos y aquellas que el ciudadano conoce más directamente. Además, esto responde seguramente a varios factores, entre los que destacan tanto la capacidad de gestión y respuesta innovadora a las

A \& C R. de Dir. Administrativo e Constitucional, Belo Horizonte, ano 4, n. 16, p. 29-64, abr./jun. 2004 
demandas sociales como la receptividad y el trato cercano a los ciudadanos.

El nivel local es el que de modo cuantitativamente más importante enraíza las instituciones con el tejido social; de ahí la importancia de fomentar mecanismos de participación, la mejora de la información, la eficacia de la actuación pública y la atención a los criterios de los usuarios de los servicios públicos.

A este respecto, se trata de que los ayuntamientos se configuren como abiertos a la participación, ya que en el diseño institucional de los gobiernos locales cobra creciente importancia la institucionalización de mecanismos de participación y concertación ciudadanas, una de las funciones mediáticas más importantes para el gobierno local.

Ha de significarse además que la participación ciudadana no solamente se produce a través del voto, sino también a través de la presentación de candidatos, la provisión de numerosos cargos públicos de representación, la participación en un variado tipo de comisiones..etc. En definitiva, el nivel local es el que de modo cuantitativamente más importante enraíza las instituciones con el tejido social, ya que en este nivel, se fomentan los mecanismos dirigidos a la mejor información de la Administración, a la eficacia de una actuación pública sensible a las demandas populares y a los criterios de los usuarios de los servicios públicos.

Los municipios han de servir para incorporar fórmulas innovadoras de refuerzo de la participación política, a través de mecanismos consultivos, del derecho de petición, de consejos de participación, mecanismos todos ellos que acercan la Administración y el Gobierno a los ciudadanos.

Esto es así porque lo local constituye el contrapeso político necesario a la globalización a la que estemos asistiendo hoy en día. La conservación de la identidad local es una necesidad esencial en este mundo globalizado como contrapeso a los procesos de pérdida de identidad y de alejamiento de las instancias de decisión económicas y políticas de los ciudadanos.

Por otro lado, la participación ha de ser una forma de lograr una mayor integración y cohesión sociales y servir como escuela de ciudadanía, profundizando la democracia para hacerla no solo formal y representativa, sino también real y participativa, evitando la apatía y el individualismo.

El objetivo en este terreno ha de ser doble: acercar los poderes locales a los ciudadanos y utilizar la participación como vía para su legitimación, ya que, la legitimación de los gobiernos locales presenta hoy la necesidad de eficiencia y eficacia en su actuación así como evaluación participativa. La

A \& C R. de Dir. Administrativo e Constitucional, Belo Horizonte, ano 4, n. 16, p. 29-64, abr./jun. 2004 
democracia representativa consiste no sólo, como acabo de mencionar, en participar en las elecciones a través del voto sino también en los procesos de deliberación y en la implementación, evaluación y gestión de las políticas públicas. La democracia, y más en el ámbito local, no es sólo votar, sino deliberar, discutir, valorar.

Este conjunto de realidades ha de conducirnos hacia un nuevo modo de funcionamiento de los gobiernos locales que podría ser caracterizado por las notas siguientes: posburocrático, descentralizado y desconcentrado, de calidad, flexible, responsable, eficaz, eficiente, orientado hacia los resultados y al servicio del público, considerado como ciudadano.

Esta potenciación de la vida local ha permitir entre otras cosas una mayor participación y representación sobre todo a través de nuevos cauces, destacándose especialmente que la participación es un estilo de gobernar diferente y que implica un desarrollo de la tarea educadora de la ciudadanía local y de su cultura cívica.

\section{La participación en la ley de medidas para la modernización local}

Las consideraciones precedentes sobre la relevancia de la participación en la reforma administrativa, en el contexto de las nuevas políticas públicas y, especialmente en el espacio local, nos ayudan sobremanera a poner en suerte este último epígrafe, dedicado a analizar específicamente el tratamiento dado por el legislador de 2003 dedica a este tema.

Para empezar, nada mejor que leer con cierto detenimiento la exposición de motivos de la ley de medidas para la modernización del Gobierno local para conocer hasta que punto la participación está presente en la "mens legislatoris".

Pues bien, en el párrafo I, cuando el legislador censura el uniformismo organizativo del modelo de la Ley de 1985 y al recordar que uno de los objetivos del denominado Pacto Local era - y es - mejorar los mecanismos de control del Pleno sobre los Presidentes de las Entidades locales, señala que es necesario "responder a la exigencia de un debate político abierto y creativo sobre las principales políticas de la ciudad”. Es decir, potenciar la función de control del Pleno está lógicamente relacionada con el robustecimiento de un espacio público deliberativo de mayor calidad y más representativo, por tanto, de las sensibilidades y opiniones representadas por los partidos políticos elegidos por los vecinos. Es esta una primera 
intención del legislador que se sitúa en una línea de continuidad con la reforma de la Ley de 1985 operada en virtud del Pacto Local.

Por otra parte, dentro de la voluntad reformista de esta Ley, nos encontramos precisamente con que en los últimos dieciocho años - señala su exposición de motivos - "se ha manifestado como insuficiente, por su carácter nuevamente declarativo, el tratamiento que de la participación se hace en la LBRL. En este tercer ámbito, existe una clara tendencia continental a reforzar las posibilidades de participación y de incidencia de los ciudadanos en el Gobierno local, para evitar o corregir, en el contexto de un mundo globalizado, el alejamiento de los ciudadanos de la vida pública. En esta materia, hay que destacar la procedencia de incrementar la participación y la implicación de los ciudadanos en la vida local, lo que no constituye en modo alguno un elemento contradictorio con los anteriores, sino que, por el contrario, los complementa y enriquece. Y si bien es cierto que en este ámbito hay que conceder amplios márgenes a la potestad de autoorganización de las Entidades locales, también lo es que la legislación básica estatal debe contener unos estándares mínimos concretos que permitan la efectividad de esa participación”.

El legislador, como hemos señalado con anterioridad, se muestra preocupado por el progresivo alejamiento de los ciudadanos de la política y piensa, con razón, que en el espacio local es desde dónde se debe empezar a combatir este mal de nuestro tiempo. Mal que no es de exclusiva responsabilidad de quienes se inhiben sino que, también, los propios dirigentes públicos tienen su cuota de responsabilidad. En cualquier caso, siendo conscientes de que la participación real no depende sólo de normas y procedimientos sino que constituye una manifestación capital de la condición social del ser humano, un paso razonable lo constituye, en efecto, el establecimiento de "mínimos" que se remiten a la reserva reglamentaria. Insisto, como ya he comentado en este estudio, la participación es una expresión cívica que hoy, guste o no, no es que sea muy elevada. Por tanto, junto a la apertura de cauces normativos y procedimentales, es muy importante fomentar y facilitar una educación cívica de altura pues, de lo contrario, nos podríamos encontrar con la paradoja de que abrimos cauces y espacios, una participación, o bien dirigida desde el vértice o bien a la medida de los llamados profesionales de la participación ante la permanente inactividad de las mayorías.

En este sentido, pienso, debe entenderse otro parágrafo esencial

A \& C R. de Dir. Administrativo e Constitucional, Belo Horizonte, ano 4, n. 16, p. 29-64, abr.jun. 2004 
de la exposición de motivos en materia de participación. Lo encontramos en el punto III: "En materia de participación ciudadana, se establecen unos estándares mínimos que constituyen los mecanismos necesarios para su potenciación: el establecimiento de la necesidad de reglamentos orgánicos en todos los municipios en materia de participación ciudadana, que determinen y regulen los procedimientos y mecanismos adecuados para hacerla efectiva; la aplicación de las nuevas tecnologías de la información y la comunicación con los vecinos, así como para facilitar la realización de trámites administrativos, y la introducción en la legislación básica sobre régimen local de las iniciativas ciudadanas, que pueden constituir un importante instrumento participativo, que puede dar lugar, incluso, a consultas populares".

En este punto, pues, hay que superar el posible efecto "taumatúrgico" de los reglamentos teniendo presente la relevancia de una educación cívica en los valores y cualidades democráticas. Lo mismo debe predicarse del sentido instrumental de las nuevas tecnologías. Por supuesto que sí los vecinos están en condiciones de entrar en la red o de dirigirse al Ayuntamiento a través de ordenadores propios, hemos avanzado notablemente. Así, las nuevas tecnologías son una oportunidad estupenda para la libertad y la participación. Pero siempre que, en efecto, los canales estén abiertos y con facilidad se puedan plantear iniciativas, quejas o sugerencias. Si resulta que, en realidad, ni resulta tan fácil, ni causa algún efecto la comunicación, entonces cundirá un cierto desánimo. No se debe olvidar, por otra parte, que es una media altamente positiva, la introducción de las iniciativas ciudadanas. Es una manifestación de la participación que puede enriquecer con la vitalidad de lo real las políticas públicas locales y, sobre todo, puede llevar a que se convoquen determinadas consultas populares.

En realidad, como se reconoce en la exposición de motivos "los diversos mecanismos participativos creados e impulsados por la ley, tanto de carácter general como los que más adelante se señalan para los municipios a los que resulta de aplicación el Título X de la Ley, colocan a nuestro régimen local en la línea avanzada de promoción de la participación que está adquiriendo cuerpo en todo el continente, impulsada por el Consejo de Europa, y de la que es una importante manifestación la Recomendación de su Comité de Ministros Rec (2001) 19, que ha servido de fuente de inspiración para esta reforma". En realidad, en materia de participación, España se inscribe entre los países vanguardistas por mor, en efecto, de 
la introducción de numerosas iniciativas patrocinadas por el Consejo de Europa a través de su Comité de Ministros. Además de que, es verdad, los artículos 131 y 132 de la Ley de Bases, según la regulación de esta reforma, preveen la existencia obligatoria del Consejo Social y de la Comisión de Sugerencias y Reclamaciones para las "grandes ciudades", no veo inconveniente en que, en el resto de Entidades Locales en que así se decida, a través de la competencia que tiene el Pleno (artículo 22.1.d)) para aprobar el reglamento orgánico y las ordenanzas, puedan también establecerse órganos similares u análogos a los previstos en la Ley para las grandes ciudades. La autonomía local así lo permite y, como sabemos, si de lo que se trata en la Ley es de mejorar el régimen local general y atender a las especialidades del fenómeno urbano, resulta una manifestación de la autonomía local general la mejora de la participación en todos los Entes locales, sea cual sea su población o su condición institucional.

Dentro del régimen especial para las ciudades que reúnan los requisitos del nuevo Título X de la Ley de bases, el artículo 128 prevee también la existencia obligatoria de Distritos, que según la exposición de motivos "constituyen un instrumento esencial para el desarrollo de políticas de proximidad y participación en los municipios altamente poblados, tanto desde la perspectiva de las desconcentración de funciones como desde la de la participación ciudadana”. Igualmente, la exposición de motivos señala que "debe destacarse el establecimiento del Consejo social de la ciudad, como mecanismo participativo del carácter consultivo de las principales organizaciones económicas y sociales del municipio, centrado esencialmente en el campo del desarrollo local y de la planificación estratégica urbana, ámbitos éstos en las que están adquiriendo una importancia esencial en las políticas locales". Y, finalmente, el legislador nos confiesa que "otra novedad relevante en el ámbito organizativo es el establecimiento de un órgano para la participación de los vecinos y la defensa de sus derechos. La ley ha puesto el acento en este ámbito al prever la necesidad de que esta defensa mediante la creación de una Comisión de Sugerencias y Reclamaciones, que estará formada por miembros del Pleno, con participación de todos los vecinos". Bienvenidos sean los instrumentos de participación siempre que representen la vitalidad de la realidad y que permitan que los vecinos se sientan interpelados e implicados en las políticas públicas locales. Por eso, el Consejo Social de la ciudad, si representa la realidad, será un instrumento que posibilite un eficaz y abierto planteamiento del desarrollo municipal.

A \& C R. de Dir. Administrativo e Constitucional, Belo Horizonte, ano 4, n. 16, p. 29-64, abr.jun. 2004 
Una vez finalizado el comentario de los párrafos de la exposición de motivos de la ley en sede de participación, es momento de una glosa de aquellos preceptos en los que se hace referencia a la materia que estamos estudiando.

El nuevo artículo 18 se refiere a los derechos y deberes de los vecinos. En su párrafo 1 letra b) se señala que tiene esta consideración — derecho y deber - "la participación en la gestión municipal de acuerdo con las leyes y, en su caso, cuando la colaboración con carácter voluntario de los vecinos sea interesada por los órganos de gobierno y administración municipal”. Es decir, con carácter general la participación en la gestión está limitada por lo establecido en las leyes. Nada nuevo en este punto. Y, con carácter especial, los vecinos pueden ser invitados a participar en la gestión municipal cuando así lo decidan las autoridades locales. Se deja, por tanto, la puerta abierta a lo que se determine, más en concreto, en los reglamentos de participación ciudadana. También establece el artículo 18.1.e) el derecho y deber de los vecinos a "ser informado, previa petición razonada, y dirigir solicitudes a la Administración municipal en relación a todos los expedientes y documentación, de acuerdo con lo previsto en el artículo 105 de la Constitución”. Se trata, pues, de regular el derecho a la información que tienen los ciudadanos. Para ello, es lógico, se obliga al vecino en cuestión a que su petición sea razonada y motivada pues no se debe olvidar que una de las nuevas tendencias administrativas en esta materia, introducida por la Ley 4/1999, es precisamente una mayor y mejor motivación de los actos administrativos. Por lo que se refiere a participar en los procedimientos administrativos municipales, debe recordarse aquí el régimen general, y que, obviamente, el vecino que acuda a esta vía debe encontrarse legitimado para hacerlo de acuerdo con lo dispuesto en la ley de régimen jurídico. Por supuesto, son de aplicación los límites del artículo 105 de la Constitución relativos a los supuestos de seguridad y defensa del Estado, así como el respeto a la intimidad y a la averiguación de delitos, deben ser tenidos en cuenta.

La ley que estudiamos, abre, en la nueva redacción que se da a los derechos y deberes del vecino, la posibilidad (artículo 18.1.f)) de "pedir la consulta popular en los términos previstos en la ley" de acuerdo con el nuevo artículo 70 bis de la Ley de 1985 y a tenor del procedimiento del artículo 71 de la Ley de bases. Lógicamente, el artículo 18.1.h) hace referencia al derecho deber de "ejercer la iniciativa popular en los términos 
del artículo 70 bis", iniciativa que, como veremos, puede dar lugar a una consulta popular.

Puede decirse que el precepto central en materia organizativa para promover la participación es el nuevo artículo 24, que prescribe: "1. Para facilitar la participación ciudadana en la gestión de los asuntos locales y mejorar ésta, los Municipios podrán establecer órganos territoriales de gestión desconcentrada con la organización, funciones y competencias que cada Ayuntamiento les confiera, atendiendo a las características del asentamiento de la población en el término municipal, sin perjuicio de la unidad de Gobierno y gestión del Municipio. 2. En los Municipios señalados en el artículo 121 será de aplicación el régimen de gestión desconcentrada establecido en artículo 128". Tenemos pues, traslado de competencias a órganos municipales más cercanos a los vecinos para así facilitar y mejorar la participación. En los supuestos de las denominadas "grandes ciudades" es obligatorio la constitución de Distritos, igualmente con la finalidad de propiciar la participación vecinal.

El nuevo artículo 70 bis de la Ley de bases, regulado según la reforma que estamos analizando, es el principio capital en materia de participación: remite a los reglamentos los procedimientos concretos para hacer efectiva la participación de los vecinos en los asuntos de la vida pública local tanto en el Municipio como en los Distritos, en caso de que existen (párrafo $1^{\circ}$ ). Serán, pues, los reglamentos orgánicos la sede adecuada para regular las formas concretas de la participación. Es muy importante llamar la atención de que el reglamento debe abrir cauces, espacios a la libre participación o participación libre, evitando lo que se ha denominado participación dirigida o vertical, tendencia que se aprecia en no pocas realidades administrativas y gubernamentales que se anticipan a la libre expresión de los intereses colectivos, encauzando sutilmente todas cuantas asociaciones aspiren a plantear legítimas reivindicaciones y aspiraciones.

En el párrafo segundo del artículo 70 bis se señala que "los vecinos que gocen del derecho de sufragio activo en las elecciones municipales podrán ejercer la iniciativa popular, presentando propuestas de acuerdos o actuaciones o proyectos de reglamentos en materias de la competencia municipal. Dichas iniciativas deberán ir suscritas al menos por el siguiente porcentaje de vecinos del municipio:

- Hasta 5000 habitantes, el 20 por ciento;

A \& C R. de Dir. Administrativo e Constitucional, Belo Horizonte, ano 4, n. 16, p. 29-64, abr./jun. 2004 
- De 5000 a 20.000 habitantes, el 15 por ciento;

- A partir de 20.000 habitantes, el 10 por ciento.

Tales iniciativas deberán ser sometidas a debate y votación en el Pleno, sin perjuicio de que sean resueltas por el órgano competente por razón de la materia. En todo caso, se requerirá el previo informe de legalidad del Secretario del Ayuntamiento, así como el Informe del interventor cuando la iniciativa afecta a derechos y obligaciones de contenido económico del Ayuntamiento. En el municipio a que se refiere el artículo 121 de esta ley, el informe será emitido por el Secretario General del Pleno y cuando la iniciativa afecta a derechos y obligaciones de contenido económico, el informe será emitido por el Interventor general municipal. Lo dispuesto en este apartado me entiende sin perjuicio de la legislación autonómica en esta materia. Tales iniciativas pueden llevar incorporada una propuesta de consulta popular local, que será tramitada en tal por el procedimiento y con los requisitos previstos en el artículo 71”.

En este párrafo 2, pues, se ha tenido presente que el espacio local es el mejor laboratorio democrático en el que poner en marcha experiencias de participación real. Así, se considera a los vecinos como sujetos activos de la vida pública local y se les permite que, con los quórums establecidos, puedan ejercer una iniciativa popular que va más allá de las simples propuestas llegando a poder expresarse en forma de proyectos de reglamentos. Este es un tema que conviene subrayar porque se abren espacios bien amplios en los que la realidad plural del Municipio se puede incorporar, nada más y nada menos, que a la elaboración de las normas locales de mayor trascendencia. Es una forma de enriquecer el interés público local con las libres aportaciones de la vida real del municipio, incluso, dando un paso más, se da entrada, vía iniciativa popular, a la consulta con los requisitos conocidos del artículo 71 de la Ley de bases. Hay que reconocer que se ha ampliado la posibilidad de la participación vecinal y que ahora lo relevante es que estos caminos sean transitados de forma coherente y plural por los vecinos.

En materia de participación, la exposición de motivos hacía una referencia a las tecnologías de la información como instrumentos para su facilitación y desarrollo. Por eso, el número tercero del artículo 70 bis señala: "Asimismo, las Entidades locales, y especialmente los Municipios, deberán impulsar la utilización interactiva de las tecnologías de la información y la comunicación para facilitar la participación y la comunicación con los vecinos, para la presentación de documentos y para la realización de 
trámites administrativos, de encuestas y, en su caso, de consultas ciudadanas. Las Diputaciones provinciales, cabildos y consejos singulares colaborarán con los municipios que, por su insuficiente capacidad económica y de gestión, no puedan desarrollar en grado insuficiente el deber establecido en este apartado".

Las nuevas tecnologías de la información pueden ser unos magníficos caminos para la participación siempre que los vecinos estén preparados para expresar sus legítimos intereses y aspiraciones y siempre que puedan, en número relevante, contribuir a las encuestas o consultas que se establezcan desde el Municipio. Son formas de democracia electrónica muy positivas pero que, insisto, deben contar con un mero creciente de participantes. Las Diputaciones, Cabildos y Consejos singulares tienen la obligación como consecuencia de su básica función de asistencia jurídica y técnica, de ayudar a los Municipios son escasos recursos económicos a poner en marcha meras tecnologías con el fin de fomentar y desarrollar la participación.

Hasta aquí, el régimen general de la participación tal y como lo ha establecido el legislador de 2003. Ya en materia de los municipios que la ley llama de "gran población", son de destacar, para finalizar, los artículos $123,128,131$ y 132 .

En el artículo 123, en sede de atribuciones del Pleno, el legislador señala en el párrafo $1^{\circ}$ letra c) que es competencia del Pleno la aprobación y modificación de los reglamentos de naturaleza orgánica. Tendrán en todo caso naturaleza orgánica: la regulación del Consejo Social de la ciudad, la regulación de la Comisión Especial de Sugerencias y Reclamaciones, la regulación de los órganos complementarios y de los procedimientos de participación ciudadana y, la división del Municipio en Distritos, y la determinación y regulación de los órganos de los Distritos y de las competencias de sus órganos representativos y participativos, sin perjuicio de las atribuciones del Alcalde para determinar la organización y las competencias de su administración ejecutiva. Es decir, será en el marco del Pleno como máxima expresión de la función deliberativa y de control municipal, donde se aprueben los reglamentos de participación y las normas orgánicas donde se regulen el Consejo Social, la Comisión Especial de Sugerencias y Reclamaciones, así como la división en los Distritos y sus funciones participativas.

En el artículo 128 se establece la obligación, para los Municipios

A \& C R. de Dir. Administrativo e Constitucional, Belo Horizonte, ano 4, n. 16, p. 29-64, abr./jun. 2004 
de "gran población", de constituir Distritos "como divisiones territoriales propias, dotadas de órganos de gestión desconcentrada, para impulsar y desarrollar la participación ciudadana en la gestión de los asuntos municipales y su mejora". En las grandes ciudades, parece lógico que se acerque la Administración a los vecinos y que estas estructuras desconcentradas propicien espacios de participación que permitan el afloramiento de la vital y plural realidad que rodea la vida de los Distritos. Se trata de generalizar una experiencia de probada eficacia en el Derecho Comparado, así como en Madrid y Barcelona.

El Consejo Social también proviene del Derecho Comparado Europeo y es un órgano de representación y participación de naturaleza consultiva de las principales organizaciones económicas y sociales de la ciudad en todo lo relativo al desarrollo local, planificación estratégica y grandes proyectos urbanos. Es, en definitiva, un órgano que, con sus informes y dictámenes, ayudará a los gestores municipales a la necesaria sensibilidad social que debe guiar las principales políticas públicas locales.

Y, finalmente, el artículo 132 establece, como un órgano para la defensa de los derechos de los vecinos, una Comisión especial de Sugerencias y Reclamaciones cuyo funcionamiento, de naturaleza orgánica, aprobará el Pleno. Es una especie de Defensor colegiado del Pueblo, al menos en lo que se refiere a sus principales funciones. La Comisión estará formada por representantes de todos los grupos que integran el Pleno de forma proporcional al número de miembros que tengan. La Comisión, artículo 132.2, podrá supervisar la actividad de la Administración municipal como el Defensor del Pueblo - y deberá dar cuenta al Pleno, mediante un Informe anual, de las quejas presentadas y de las deficiencias observadas en el funcionamiento de los servicios municipales, con especificación de las sugerencias o recomendaciones no admitidas por la Administración municipal. Además, en circunstancias excepcionales de gravedad, podrá realizar informes de extraordinarios.

En fin, la regulación de la participación en la ley de medidas para la modernización del Gobierno local es una regulación que pone las bases para que, en función de la educación cívica, las políticas públicas locales sean más abiertas, plurales, dinámicas y complementarias. Esperemos que los reglamentos de participación ciudadana, que las nuevas tecnologías, que los Distritos, el Consejo Social y la Comisión de Sugerencias y Reclamaciones, éstas últimas para que las ciudades de "gran población”,colmen las 
expectativas con las que el legislador las ha establecido.

A \& C R. de Dir. Administrativo e Constitucional, Belo Horizonte, ano 4, n. 16, p. 29-64, abr./jun. 2004 